\title{
HUBUNGAN KINERJA PERAWAT DENGAN KEPUASAN PASIEN DI INSTALASI GAWAT DARURAT RSU GMIM PANCARAN KASIH MANADO
}

\author{
Rifka E. Rama \\ Mona Wowor \\ Lenny Gannika \\ Program Studi Ilmu Keperawatan Fakultas Kedokteran \\ Universitas Sam Ratulangi \\ Email : rifkaenjeliarama@gmail.com
}

\begin{abstract}
Abstrack: Performance is a person's achievement with regard to all tasks assigned to him. Patient satisfaction can be influenced by factors such as, not in line with expectations and reality, service and personnel behavior is unsatisfactory, the physical condition of the environment, the cost is too high, and the promotion is not in accordance with reality. The purpose of this research is to identify The Correlation between nurse's performances and patient's satisfaction in Emergency Room of RSU GMIM Pancaran Kasih Manado. This research used cross sectional approach. The respondents are consisted of 94 patients and the sampling technique used purposive sampling. Questionnaires were used as the measuring instrument. The result of this research was analyzed by statistical analysis used chi square. The result indicates value $(p=0,000)$ which means the Ha was accepted or there is correlation between nurse's performance and patient's satisfaction in Emergency Room of RSU GMIM Pancaran Kasih Manado. In conclusion this study shows that there are relations between the nurse performance and the patient's satisfaction in Emergency Room of GMIM Pancaran Kasih Public Hospital.
\end{abstract}

Keywords : Nurse performance, Patient satisfaction

\begin{abstract}
Abstrak: Kinerja merupakan pencapaian atau prestasi seseorang berkenaan dengan seluruh tugas yang dibebankan kepadanya. Kinerja perawat yang andal, mandiri, dan professional akan membuat pasien merasa puas melalui asuhan keperawatan yang diberikan. Kepuasan pasien dapat dipengaruhi oleh faktor-faktor seperti, tidak sesuai harapan dan kenyataan, layanan dan perilaku personel kurang memuaskan, kondisi fisik lingkungan tidak menunjang, biaya terlalu tinggi, dan Promosi/iklan tidak sesuai dengam kenyataan. Tujuan penelitian ini untuk mengidentifikasi hubungan kinerja perawat dengan kepuasan pasien di IGD RSU GMIM Pancaran Kasih Manado. Desain Penelitian ini menggunakan pendekatan cross sectional. Responden terdiri dari 94 pasien dengan teknik pengambilan sampel dengan cara Purposive Sampling. Pengumpulan data menggunakkan kuesioner. Hasil Penelitian uji kolerasi yang digunakan dalam penelitian ini adalah uji Chi Square. Hasil penelitian menunjukkan nilai $(P=0,000)$ yang berarti Ha di terima atau ada hubungan yang signifikan antara kinerja perawat dengan kepuasan pasien di IGD RSU GMIM Pancaran Kasih Manado. Kesimpulan hasil penelitian ini menunjukkan bahwa terdapat hubungan yang signifikan antara kinerja perawat dengan kepuasan pasien di IGD RSU GMIM Pancaran Kasih Manado.
\end{abstract}

Kata kunci : Kinerja Perawat, Kepuasan Pasien 


\section{PENDAHULUAN}

Rumah Sakit sebagai pemberi layanan kesehatan yang didalamnya terdiri dari perawat, dokter, dan para medis lainnya yang dituntut untuk mampu memberikan pelayanan yang memuaskan pasien. Ketika pasien merasakan kepuasan dalam pelayanan kesehatan yang diberikan, itu dapat berdampak positif pada proses kesembuhan pasien, kepercayaan dalam pemberian tindakan keperawatan, dan penilaian dari pasien terhadap kinerja perawat di Instalasi Gawat Darurat (Luan, dkk, 2017). Kinerja perawat yang andal, mandiri, dan professional akan membuat pasien merasa puas melalui asuhan keperawatan yang diberikan dan pasien akan membuat kesan tersendiri tentang bagaimana pasien ditangani dari awal datang ke rumah sakit sampai pasien meninggalkan rumah sakit (Suwardana, 2014).

Instalasi Gawat Darurat (IGD) merupakan pintu pertama bagi pasien dalam memperoleh tindakan perawatan baik dalam keadaan gawat darurat maupun tidak dalam keadaan gawat darurat. Oleh sebab itu, IGD mempunyai peran penting dalam memberikan kepuasan pada pasien melalui kinerja yang di berikan oleh tenaga medis khususnya perawat dalam menangani dan memberikan asuhan keperawatan sebaik mungkin. Kejadian gawat darurat biasanya berlangsung secara tiba-tiba sehingga sulit memprediksi kapan terjadinya sehingga pemerintah menuntut setiap rumah sakit untuk memenuhi kebutuhan sebagai strategi utama yang berorientasi pada kepuasan pasien (Riskesdas, 2013).

Hasil studi dari National Health Service di Inggris bahwa pelayanan perawatan mempengaruhi tingkat kepuasan pasien (Leading Practices in Emergency Departement, 2010), menurut suryani (2010:2) menjelaskan penelitian di Amerika Serikat tentang kepuasan pelayanan pasien di IGD. Hasil penelitian menunjukkan bahwa dari 10 pasien yang berkunjung ke IGD, 6 orang mengeluhkan tentang perawatan yang diberikan tidak sesuai dengan harapan, waktu tunggu yang relative lama, dan fasilitas yang ada serta pegawai yang masih kurang, dan 4 orang lainnya mengatakan ketidakpuasannya mengenai obat yang diberikan relative lama dan memiliki proses yang rumit

Indonesia menunjukkan bahwa angka kepuasan pasien di RSUD Syech Yusuf Kab. Gowa Makassar 30,0\% (Hafid, 2014). Berdasarkan penelitian yang dilakukan oleh Krisnawati dkk (2015) didapatkan sebanyak $68,42 \%$ responden mempunyai kinerja baik dan sebanyak $63,16 \%$ responden menyatakan sangat puas terhadap kinerja perawat. Berdasarkan penelitian yang dilakukan oleh Purwanto dkk (2012) sebagian besar perawat memiliki kinerja yang cukup baik sebanyak $74,7 \%$ dan sebagian besar pasien menyatakan puas sebanyak $82,8 \%$. Standar kepuasan pasien di pelayanan kesehatan ditetapkan secara nasional oleh Departemen Kesehatan. Menurut Peraturan Kementrian Kesehatan Republik Indonesia Tahun 2016 tentang Standar Pelayanan Minimal untuk kepuasan pasien yaitu di atas 95\% (Kemenkes, 2016). Bila ditemukan pelayanan kesehatan dengan tingkat kepuasan pasien di bawah 95\%, maka di anggap pelayanan kesehatan yang diberikan tidak memenuhi standar minimal atau tidak berkualitas.

Menurut Krisnawati dkk (2015), terdapat hubungan yang signifikan antara kinerja perawat dengan kepuasan pasien. Pelayanan yang diterima pasien sesuai dengan yang diperlukan dapat membuat pasien merasa puas. Menurut Purwanto dkk (2012) mengatakan kinerja perawat erat hubungan dengan kepuasan pasien, di karenakan semakin baik kinerja perawat maka akan meningkatkan kepuasan pasien. Kepuasan pasien ditentukan oleh kinerja perawat meliputi kompetensi petugas, konsultasi yang teliti, tidak ada kesalahan prosedur, dan pelayanan yang tepat waktu. Menurut Nursalam (2011) ada beberapa faktor yang mempengaruhi kepuasan pasien, yaitu: tidak sesuai harapan dan 
kenyataan, layanan selama proses menikmati jasa tidak memuaskan, perilaku personel kurang memuaskan, suasana dan kondisi fisik lingkungan yang tidak menunjang, Biaya terlalu tinggi karena jarak terlalu jauh dan harga tidak sesuai, promosi/iklan tidak sesuai dengan kenyataan. Menurut Suwardana (2014) jika pasien tidak puas maka pasien akan beralih ke Rumah sakit lainnya yang memenuhi harapan pasien, hal tersebut dikarenakan pasien merupakan aset yang sangat berharga dalam mengembangkan industri rumah sakit.

Berdasarkan studi pendahuluan yang peneliti lakukan pada tanggal 13 Oktober 2018 didapatkan jumlah kunjungan pasien IGD pada 3 bulan terakhir sebanyak 1.500 pasien, dengan wawancara terhadap 10 pasien yang melakukan kunjungan di IGD Rumah Sakit GMIM Pancaran Kasih Manado, diketahui bahwa 8 pasien mengatakan kinerja perawat sudah baik sesuai dengan harapan dan kenyataan pasien terhadap pelayanan yang diberikan yaitu perawat yang ramah serta peduli terhadap pasien dan cepat tanggap dalam memberikan asuhan perawatan kepada pasien sehingga pasien merasa puas, 2 pasien lainnya mengatakan bahwa masih kurang puas dengan pelayanan yang diberikan dengan alasan pasien harus menunggu lama untuk menerima perawatan dan merasa kurang diperhatikan. Saat peneliti berada di IGD RSU GMIM Pancaran Kasih Manado, ada berbagai macam kondisi pasien yang datang mulai dari keadaan yang gawat darurat maupun tidak dalam keadaan gawat darurat, ada pasien yang datang namun diijinkan pulang dan ada pasien yang harus tetap tinggal untuk pemeriksaan lanjutan. Dari hasil wawancara dengan pihak Rumah sakit Pancaran Kasih GMIM Manado mengatakan belum pernah dilakukan atau belum ada format penilaian tentang Kepuasan pasien khususnya pasien IGD. Berdasarkan fenomena tersebut maka peneliti tertarik untuk melakukan penelitian tentang hubungan kinerja perawat dengan kepuasan pasien di IGD RSU Gmim Pancaran Kasih Manado.

\section{METODE PENELITIAN}

Penelitian ini bersifat analitik untuk menganalisis hubungan antara kedua variabel yaitu variable independen (Kinerja Perawat) dan variabel dependen (Kepuasan Pasien). Penelitian ini menggunakan desain penelitian cross sectional. Penelitian ini dilaksanakan di IGD RSU GMIM Pancaran Kasih Manado pada bulan Desember 2018Februari 2019. Populasi penelitian ini berjumlah 1.500 pasien. Teknik pengambilan sampel pada penelitian ini dengan menggunakan rumus slovin yaitu mengambil sebagian sampel dari populasi yang ada, yaitu 94 pasien IGD. Instrumen penelitian yang digunakan untuk mengukur kinerja perawat menggunakan kuesioner yang digunakan sebelumnya oleh Prayogi (2016) yang telah diuji validitasnya. yang terdiri dari 22 item pernyataan dengan pilihan jawaban yaitu skor 5 (Selalu), skor 4 (Sering), skor 3 (kadang-kadang), skor 2 (pernah), skor 1(tidak pernah).

Pengukuran Kepuasan pasien menggunakan kuesioner yang digunakan sebelumnya oleh Prayogi (2016) terdiri dari 24 pertanyaan dengan bobot skor 5 (sangat puas), 4 (puas), 3 (cukup puas), 2 (tidak puas) dan 1 (sangat tidak puas). Pengolahan data yang diperoleh dari hasil penelitian ini diolah secara manual kemudian dilakukan penghitungan skor dan dianalisis menggunakan uji statistik melalui sistem komputerisasi dengan beberapa tahap yaitu editing, coding, processing, cleaning (Notoatmodjo, 2012). Analisa bivariat dalam penelitian ini yaitu untuk melihat hubungan kinerja perawat dengan kepuasan pasien di IGD RSU GMIM Pancaran Kasih Manado. Peneliti menggunakan uji statistic Chi Square dengan tingkat kemaknaan 95\% $(\alpha=0,05)$. 
HASIL dan PEMBAHASAN

1. Karakteristik Responden

Tabel 1. Distribusi karakteristik responden di IGD RSU GMIM Pancaran Kasih Manado.

\begin{tabular}{lcc}
\hline Kategori & n & \% \\
\hline Umur & & \\
$18-40$ & 48 & 51,1 \\
$41-60$ & 35 & 37,2 \\
$>60$ & 11 & 11,7 \\
Total & $\mathbf{9 4}$ & $\mathbf{1 0 0 , 0}$ \\
Pendidikan & & \\
SD & 10 & 10,6 \\
SMP & 18 & 19,1 \\
SMA & 41 & 43,6 \\
Sarjana & 25 & 26,6 \\
Total & $\mathbf{9 4}$ & $\mathbf{1 0 0 , 0}$ \\
Pekerjaan & & \\
PNS & 5 & 5,3 \\
Swasta & 32 & 34,0 \\
Wiraswasta & 3 & 3,2 \\
Wirausaha & 9 & 9,6 \\
Pendeta & 5 & 5,3 \\
Buruh & 8 & 8,5 \\
Tani & 6 & 6,4 \\
IRT & 15 & 16,0 \\
Pensiunan & 4 & 4,3 \\
Mahasiswa & 7 & 7,4 \\
Total & $\mathbf{9 4}$ & $\mathbf{1 0 0 , 0}$ \\
Jenis & & \\
Kelamin & & 54,3 \\
Laki laki & 51 & 45,7 \\
Perempuan & 43 & $\mathbf{1 0 0 , 0}$ \\
Total & $\mathbf{9 4}$ & \\
\hline Sumber: Data Priner & &
\end{tabular}

Sumber : Data Primer 2019

Hasil penelitian karakteristik responden berdasarkan umur menunjukkan bahwa dari 94 responden (100\%) yang paling banyak berdasarkan usia dewasa awal berjumlah 48 responden $(51,1 \%)$ dan yang paling sedikit usia dewasa lanjut berjumlah 11 responden (11,7\%). Penelitian ini didukung oleh hasil penelitian Wardani dan Sugiarsi (2014) bahwa karakteristik pasien yang datang di Instalasi Gawat Darurat pada umumnya usia dewasa awal. Karakteristik responden berdasarkan pendidikan menunjukkan bawa dari 94 responden (100\%) didapati sebagian besar responden berpendidikan terakhir SMA berjumlah 41 responden $(43,6 \%)$. Semakin tinggi pendidikan sesorang maka akan semakin mengerti tentang kesehatan. Seseorang dengan pendidikan lebih rendah cenderung mempersepsikan pelayanan baik di bandingkan dengan yang berpendidikan tinggi (Tjiptono, 2007). Karakteristik responden berdasarkan pekerjaan menunjukkan bahwa dari 94 responden $(100 \%)$ didapati sebagian besar responden bekerja sebagai Pekerja Swasta berjumlah 32 responden $(34,0 \%)$.

Penelitian Tataming dkk (2015) menyatakan bahwa tidak ada perbedaan bagi pasien yang bekerja maupun tidak bekerja, karena dalam rumah sakit baik pasien yang bekerja maupun tidak bekerja bisa mendapatkan pelayanan yang menurut mereka bisa memuaskan. Karakteristik responden berdasarkan jenis kelamin menunjukkan bahwa dari 94 responden (100\%) yang memiliki jumlah paling banyak yaitu laki-laki sebanyak 51 responden $(54,3 \%)$, sedangkan perempuan hanya sebanyak 43 responden $(45,7 \%)$. Penelitian ini sejalan dengan penelitian yang dilakukan oleh Deviantony dkk (2016) menunjukkan dari 78 pasien (100\%) bahwa yang memiliki jumlah paling banyak berkunjung ke IGD berdasarkan jenis kelamin yaitu laki-laki 43 pasien $(55,1 \%)$ sedangkan perempuan sebanyak 35 pasien $(44,9 \%)$.

\section{Analisa Univariat}

Tabel 2. Berdasarkan Distribusi Responden Kinerja Perawat

\begin{tabular}{clc}
\hline Kinerja Perawat & $\mathbf{n}$ & $\mathbf{\%}$ \\
\hline Baik & 56 & $59,6 \%$ \\
Kurang Baik & 38 & $40,4 \%$ \\
\hline Total & $\mathbf{9 4}$ & $\mathbf{1 0 0 \%}$
\end{tabular}

Sumber : Data Primer 2019

Hasil penelitian menunjukkan bahwa dari 94 responden di dapati kinerja perawat yang Baik sebanyak 56 responden $(59,6 \%)$ dan Kurang Baik sebanyak 38 responden (40,4\%). Selama peneliti melakukan penelitian di IGD RSU GMIM Pancaran Kasih Manado, responden menyatakan Kinerja perawat Baik dengan alasan perawat selalu berpakaian rapi, 
menggunakan tanda pengenal, perawat menghargai dan menghormati hak responden, perawat menerima responden dengan baik, perawat memenuhi kebutuhan fisiologis responden, perawat rutin memeriksa status status vital sign (suhu, tekanan darah, respirasi, dan nadi), perawat memberikan rasa aman dan keselamatan pada responden. Responden yang menyatakan kinerja perawat kurang baik dengan alasan perawat tidak sabar saat memberikan pelayanan. Triwibowo (2013) Kinerja dapat diartikan melalui kepatuhan perawat professional dalam melakukan asuhan keperawatan sesuai standar keperawatan.

Tabel 3. Distribusi Responden Berdasarkan Kepuasan pasien

\begin{tabular}{ccc}
\hline Kepuasan Pasien & $\mathbf{n}$ & $\boldsymbol{\%}$ \\
\hline Puas & 69 & $73,4 \%$ \\
Kurang Puas & 25 & $26,6 \%$ \\
\hline Total & $\mathbf{9 4}$ & $\mathbf{1 0 0 \%}$ \\
\hline
\end{tabular}

Sumber : Data Primer 2019

Hasil penelitian menunjukkan bahwa dari 94 responden (100\%) di dapati kepuasan pasien Puas dengan pelayanan keperawatan sebanyak 69 responden $(73,4 \%)$, dan kurang puas dengan pelayanan keperawatan sebanyak 25 pasien $(26,6 \%)$. Hasil penelitian yang peneliti lakukan dengan responden di instalasi gawat darurat, sebagian besar responden merasa puas dengan alasan perawat cepat dalam menerima responden dan cepat saat memberikan pelayanan, responden puas dengan kemampuan perawat dalam merawat dan menjawab pertanyaan reponden, keterampilan perawat, dan kemantapan perawat dalam melakukan tindakan. Responden yang kurang puas dengan alasan perawat kurang sopan dan kurang sabar selama merawat pasien Penelitian ini sejalan dengan penelitian yang dilakukan oleh Kaban dkk (2015) dengan judul penelitian Kepuasan Pasien di Instalasi Gawat Darurat RSUP Prof. Dr. R. D. Kandou Manado yang menyatakan kepuasan pasien adalah suatu tolak ukur kualitas pelayanan yang dirasakan pelanggan/pasien dibagi dengan apa yang menjadi kebutuhan pasien, keinginan pasien, dan harapan pasien itu sendiri.

\section{Analisa Bivariat}

Tabel 4. Hubungan Kinerja Perawat dengan Kepuasan Pasien Di Instalasi Gawat Darurat RSU GMIM Pancaran Kasih Manado

\begin{tabular}{|c|c|c|c|c|c|c|c|}
\hline \multirow{3}{*}{$\begin{array}{l}\text { Kinerja } \\
\text { Perawat }\end{array}$} & \multicolumn{6}{|c|}{ Kepuasan pasien } & \multirow{3}{*}{$\begin{array}{c}\text { p- } \\
\text { value }\end{array}$} \\
\hline & \multicolumn{2}{|c|}{ Puas } & \multicolumn{2}{|c|}{$\begin{array}{c}\text { Kurang } \\
\text { Puas }\end{array}$} & \multicolumn{2}{|c|}{ Total } & \\
\hline & $\mathbf{n}$ & $\%$ & $\mathbf{n}$ & $\%$ & $\mathbf{n}$ & $\%$ & \\
\hline Baik & 49 & 87.5 & 7 & 12.5 & 56 & 100 & \\
\hline $\begin{array}{l}\text { Kurang } \\
\text { Baik }\end{array}$ & 20 & 52.6 & 18 & 47.4 & 38 & 100 & 0,000 \\
\hline Total & 69 & 73.4 & 25 & 26.5 & 94 & 100 & \\
\hline
\end{tabular}

Sumber : Data Primer 2019

Hasil penelitian menunjukkan bahwa $49(87,5 \%)$ responden yang menyatakan kinerja perawat baik dan Puas dengan pelayanan perawat, $20 \quad(52,6 \%)$ responden menyatakan kinerja perawat kurang baik namun puas dengan pelayanan perawat, $7(12,5 \%)$ responden menyatakan kinerja perawat baik namun kurang puas dengan pelayanan perawat, $18(47,4 \%)$ responden menyatakan kinerja perawat kurang baik dan kurang puas dengan pelayanan perawat.

Penelitian yang dilakukan di IGD RSU GMIM Pancaran Kasih Manado, didapatkan Kinerja perawat yang Baik akan membuat responden merasa puas dengan pelayanan keperawatan yang diberikan, pada saat perawat melakukan kinerja yang sesuai dengan harapan responden maka responden akan memiliki persepsi yang baik terhadap rumah sakit dan tenaga kesehatan didalamnya khususnya perawat yang melakukan kinerja sesuai dengan standar operasional prosedur. Hal ini sejalan dengan penelitian yang dilakukan oleh Purwanto dkk (2012) yang menyatakan bahwa semakin baik kinerja perawat, akan meningkatkan kepuasan pasien. Kepuasan pasien ditentukan dengan kinerja perawat, meliputi kompetensi petugas, konsultasi yang teliti, tidak ada kesalahan prosedur, dan pelayanan tepat 
waktu. Selain itu terdapat responden yang menyatakan kinerja perawat baik namun kurang puas dengan pelayanan keperawatan yang diberikan, karena kompetensi yang dimiliki oleh perawat di rumah sakit sudah cukup baik namun responden merasa tidak puas dengan alasan sudah menunggu terlalu lama untuk mendapatkan ruang perawatan. Hal ini sejalan dengan penelitian yang dilakukan oleh Hafid (2014) dimana kinerja perawat yang baik, namun masih ada juga pasien yang merasa tidak puas di karenakan tingkat perasaan sesorang setelah membandingkan kinerja atau hasil yang dirasakan dengan harapannya tidak sesuai. Terdapat responden yang menilai kinerja perawat kurang baik namun tetap merasa puas dengan pelayanan keperawatan, dengan alasan ruangan yang bersih dan nyaman saat responden beristirahat, serta lokasi rumah sakit yang tidak jauh. Penelitian ini sejalan dengan penelitian yang dilakukan oleh Nursalam (2012) yang menyatakan kepuasan pasien di pengaruhi oleh banyak faktor antara lain kulaitas produk dan jasa, harga, emosional, kinerja, estetika, karakteristik produk, pelayanan, lokasi, fasilitas, komunikasi, suasana, dan desain visual.

Terdapat responden yang menilai kinerja perawat kurang baik dan kepuasan responden kurang puas. Hal ini terjadi karena tidak terpenuhinya harapan pasien. Dengan alasan pasien mengeluh perawat kurang berkomunikasi misalnya pada saat mengukur tekanan darah atau memberikan obat, perawat kurang senyum bahkan rasa empati yang jarang sekali di tunjukkan oleh perawat. Sehingga pasien merasa kurang nyaman untuk mengungkapkan apa yang dirasakan pasien sehingga merasa tidak puas. Luan dkk (2017) menyatakan bahwa sikap peduli terhadap keadaan pasien dan dapat di andalkan kemampuannya dalam dinamika kerja untuk memberikan jasa yang sesuai dengan kebutuhan pasien dapat mendukung kepuasan pasien, karena pada dasarnya setiap pasien yang membutuhkan perawatan pasti membutuhkan perhatian dalam menyikapi berbagai keluhan yang di rasakannya selama menjalani perawatan.

Hasil uji statistic menggunakkan uji Chi square di dapatkan bahwa nilai $p$-value $(0,000)<$ alpha 0,05. Dari hasil penelitian yang dilakukan menunjukkan adanya hubungan yang signifikan antara kinerja perawat dengan kepuasan pasien di Instalasi Gawat Darurat RSU GMIM Pancaran Kasih Manado. Penelitian ini di dukung oleh Krisnawati dkk (2015) yang membuktikan bahwa terdapat hubungan yang signifikan antara kinerja perawat dengan kepuasan pasien. Penelitian yang dilakukan oleh Luan dkk (2016) menyatakan bahwa kinerja perawat yang baik merupakan jaminan kualitas pelayanan kesehatan yang diberikan terhadap pasien baik yang sakit maupun sehat. Melalui kinerja perawat diharapkan dapat menunjukkan kontribusi profesionalnya secara nyata dalam meningkatkan mutu pelayanan keperawatan, yang berdampak pada pelayanan kesehatan, dan dampak akhir pada kualitas hidup dan kesejahteraan masyarakat.

\section{SIMPULAN}

Terdapat hubungan antara kinerja perawat dengan kepuasan pasien di Instalasi Gawat Darurat RSU GMIM Pancaran Kasih Manado. Didapatkan bahwa semakin baik kinerja perawat, maka kepuasan pasien semakin puas.

\section{DAFTAR PUSTAKA}

Hafid, A.M. (2014). Hubungan kinerja perawat terhadap tingkat kepuasan pasien pengguna yankestis dalam pelayanan keperawatan di RSUD Syech Yusuf Kab. Gowa.

Kaban, W.I,. Kandou., G.D.S. Lapian, L.H.V.J,. (2015). Kepuasan pasien di instalasi gawat darurat RSUP Prof. Dr. R. D. Kandou Manado

Kementrian Kesehatan Republik Indonesia (Kemenkes). (2016). Perubahan Standar Pelayanan Minimal (SPM) Bidang Kesehatan 
Krisnawati, T., Utami, N,W., dan Lasri. (2015). Hubungan kinerja perawat dengan kepuasan pasien ruang rawat inap di Rumah Sakit Panti Waluya Malang

Leading Practices in emergency Departement Patient Experience (2010). Ontario Hospital Asociation

Luan, M. G., Prayogi, A. S., Badi'ah, A., Murwani, A. (2017). Hubungan Kinerja Perawat dengan Kepuasan Pasien di Ruang Rawat Inap RS Tk. III 04.06.03 Dr. Soetarto Yogyakarta.

Notoatmodjo, S. (2012). Metodologi Penelitian Kesehatan. Jakarta: Rineka Cipta.

Nursalam, (2012). Manajemen Keperawatan: Aplikasi dalam Praktik Keperawatan Profesional Edisi 3. Jakarta : Salemba Medika

Prayogi, A.S. (2016). Hubungan Kinerja Perawat dengan Kepuasan Pasien di Ruang Rawat Inap Rumah Sakit Tk.III Tk. III 04.06.03 Dr. Soetarto Yogyakarta

Purwanto, J.M., Handoyo., dan Utami, W. (2012). Hubungan antara kinerja perawat dengan kepuasan pasien di instalasi gawat darurat (IGD) RSUD Cilacap

Riset Kesehatan Dasar (Riskesdas). (2013). Badan Penelitian dan Pengembangan Kesehatan Kementerian RI tahun 2013

Setyoadi., Deviantony, F., dan Ahsan. (2017). Analisis faktor yang berhubungan dengan waktu tunggu pasien setelah keputusan rawat inap diputuskan di zona kuning instalasi gawat darurat RSUD dr Iskak Tulungagun Universitas Brawijaya

Suryani. (2010). Keperawatan gawat darurat
Suwardana, D, M. (2014). Hubungan Pelaksanaan Pelayanan Perawat Dengan Kepuasan Pasien Rawat Inap Di RSUD Kabupaten Bombana

Tataming, E.R., Tucunan, A.A.T., dan Rattu, A.J.M. (2015). Hubungan antara pendidikan, pekerjaan, dan kualitas pelayanan dengan kepuasan pasien rawat jalan peserta BPJS kesehatan di poliklinik penyakit dalam RSU GMIM Pancaran Kasih Manado.

Tjiptono, Fandy. (2007). Strategi pemasaran. Yogyakarta: Andi Offset

Triwibowo, C. (2013). Manajemen Pelayanan Keperawatan di Rumah Sakit. Jakarta: Trans Info Media.

Wardani, R.A.P., Sugiarsi, S. (2014). Karakteristik pasien instalasi gawat darurat periode triwulan 1 